\title{
Self and Other Ratings of Problematic Smartphone Use: The Role of Personality and Relationship Type
}

\author{
Sharon Horwood, Jeromy Anglim ${ }^{1}$
}

\begin{abstract}
Reliance on self-report to measure problematic smartphone use is a limitation of the extant literature. It is unclear whether self- and other-ratings of problematic smartphone use converge and whether correlations between personality and selfreported problematic smartphone use are distorted by common method bias. The current study provides the first comprehensive assessment of self-other agreement of problematic smartphone use and the relationship between personality and other-rated problematic smartphone use in a large sample of young adults. Focal participants $(n=$ 1,073) were Australian university students who completed measures of Big Five (IPIP) and HEXACO (HEXACO PI-R) personality, and problematic smartphone use. One or more people who knew the focal participant well $(n=2,445)$ rated the focal participant's problematic smartphone use. People rated their own smartphone use as more problematic than did others. Self- and other-ratings of problematic smartphone use correlated .38. The pattern of self-other and other-other correlations indicated that selfratings were more accurate than other-ratings. The pattern of high neuroticism and low conscientiousness predicting greater problematic smartphone use was observed for both self- and other-ratings. Findings suggest that self-report measures are reasonably valid, problematic smartphone usage is observable, and the relationship between personality and problematic smartphone use is robust.

Keywords: problematic smartphone use, personality, other-ratings, Big Five, smartphone addiction

\section{Introduction}

Smartphones have quickly become an integral component of people's everyday lives (Pew Research Centre, 2019). Despite their many benefits, research suggests that certain forms and levels of smartphone use are associated with negative health and wellbeing outcomes (Elhai, Dvorak, Levine, \& Hall, 2017; Horwood \& Anglim, 2019; Sohn, Rees, Wildridge, Kalk, \& Carter, 2019). In particular, many users express concerns that their use feels excessive, out of control, or disruptive (Chen et al., 2017; Cho, Kim, \& Park, 2017; Elhai, Rozgonjuk, Yildirim, Alghraibeh, \& Alafnan, 2019; H. Kim, Min, Min, Lee, \& Yoo, 2018; Y. Lee, Chang, Lin, \& Cheng, 2014; Li, Lepp, \& Barkley, 2015). For example, Horwood and Anglim (2018) found that $65 \%$ of young
\end{abstract}

\footnotetext{
${ }^{1}$ Citation (check publisher for updated year, volume and page numbers):
}

Horwood, S. \& Anglim, J. (2020). Self and Other Ratings of Problematic Smartphone Use: The Role of Personality and Relationship Type. Computers in Human Behavior. 106634. https://doi.org/10.1016/j.chb.2020.106634

School of Psychology, Deakin University, Geelong, Australia Data, analysis scripts, and study materials are available on the OSF at https://osf.io/k2t5h Correspondence concerning this article should be addressed to Sharon Horwood, School of Psychology, Deakin University, Locked Bag 20000, Geelong, 3220 Australia. Email: sharon.horwood@deakin.edu.au 
adults $(n=393)$ reported that they spent longer on their smartphone than they intended, and 54\% reported that they use their smartphone when they should be doing other things, and it causes them problems. Building on this, researchers have shown that personality - especially low conscientiousness and high neuroticism-is a strong correlate of self-reported problematic smartphone use (e.g. de Francisco Carvalho, Sette, \& Ferrari, 2018; Gao, Xiang, Zhang, Zhang, \& Mei, 2017; Horwood \& Anglim, 2018).

Despite the insights of the extant literature on problematic smartphone use, the literature has largely relied on self-report measurement. There has been very little research assessing the validity of self-report measurement of problematic smartphone use, and reliance on self-report measurement has attracted criticism (Elhai et al., 2018; Ellis, Kaye, Wilcockson, \& Ryding, 2018; Orben \& Przybylski, 2020; van de Mortel, 2008). Self-ratings are subject to measurement issues such as social desirability bias, lack of personal insight, and degraded recall. More importantly, an emerging debate in the literature is around whether problematic smartphone use is an objective and observable construct or whether it merely reflects internalized cultural ideas about the dangers of new technology or a general tendency for neurotic people to worry about things (Anderson \& Rainie, 2018; Orben, 2020). Concern with self-report measurement is further amplified when researchers seek to predict problematic smartphone use from other self-report measures, such as personality. In particular, it is unclear whether the strong relationships observed between personality and problematic smartphone use are inflated or distorted by subjective biases. In order to better understand the nature of problematic smartphone use and its personality correlates, and contribute to the debate surrounding the validity of the construct of problematic smartphone use, the current study sought to provide the first comprehensive assessment of other-rated problematic smartphone use.

\subsection{Problematic Smartphone Use}

Problematic smartphone use has been defined as "compulsive use that leads to impaired daily functioning in terms of productivity, social relationships, physical health, or emotional well-being" (Horwood \& Anglim, 2018, p.349). The concept of problematic smartphone use is relatively new and, as such, there is not yet any agreed upon diagnostic criteria. A few studies have reported prevalence rates for specific populations (e.g. Korean adolescents, C. Lee \& Lee, 2017; Chinese undergrauate students, Long et al., 2016), however large-scale representative prevalence studies are still forthcoming. Some researchers have likened problematic smartphone use behaviors to those of a behavioral addiction, complete with elements of craving, tolerance and withdrawal (Billieux, Maurage, Lopez-Fernandez, Kuss, \& Griffiths, 2015; Billieux, Philippot, et al., 2015; Csibi, Griffiths, Demetrovics, \& Szabo, 2019), while others have suggested that the term 'addiction' is too severe and terms such as 'problematic' or 'maladaptive' are more reflective of the degree of potential impairment a sufferer may experience (Panova \& Carbonell, 2018). Broadly, problematic smartphone use is characterized by a poor ability to limit one's usage, a tendency to become absorbed in usage, and a tendency to feel distress or worry if smartphone access is impeded. When these behaviours contribute to negative outcomes for the user (e.g. poor productivity, relationship tension, low mood, or feelings of guilt), they are considered problematic. In particular, problematic smartphone use has been associated with a number of 
physical, psychological, and social problems such as musculoskeletal pain (e.g. Ismaeel, 2019; Namwongsa, Puntumetakul, Neubert, \& Boucaut, 2018), negative affect, depression, and anxiety (e.g. Elhai et al., 2017; Elhai, Rozgonjuk, et al., 2019; Y.-J. Kim, Jang, Lee, Lee, \& Kim, 2018; Nishida, Tamura, \& Sakakibara, 2019; Wolniewicz, Tiamiyu, Weeks, \& Elhai, 2018; Yang, Fu, Liao, \& Li, 2020), and poorer quality offline social relationships (e.g. Herrero, Urueña, Torres, \& Hidalgo, 2019; Ihm, 2018; Rotondi, Stanca, \& Tomasuolo, 2017). Problematic smartphone use has also been associated with lower levels of subjective and psychological wellbeing (Horwood \& Anglim, 2019) and poorer quality and quantity of sleep (Hughes \& Burke, 2018; Schweizer, Berchtold, Barrense-Dias, Akre, \& Suris, 2017).

Despite initial evidence to the contrary, there is a debate as to whether problematic smartphone use is a real and objective psychological construct or simply the latest version of technology-induced 'moral panic' (Anderson \& Rainie, 2018; Orben, 2020). A common argument used to debunk the idea of problematic smartphone use and related technologies is that society has a long history of being overly concerned with technological advances negatively impacting health and wellbeing. From the introduction of the telephone in the late $1800 \mathrm{~s}$, to radio, television, video games, computers, and now smartphones, society has been quick to condemn new technology as addictive, intrusive, and damaging to societal wellbeing. In retrospect most fears were unfounded, although at least some concerns about technology leading to sedentary lifestyles and obesity appears to be justified (e.g. Blass et al., 2006; Kenney \& Gortmaker, 2017; Lowry, Wechsler, Galuska, Fulton, \& Kann, 2002; Tahir, Willett, \& Forman, 2019; Vandewater, Shim, \& Caplovitz, 2004).

Another argument that complicates the question of whether problematic smartphone use is a valid construct is the variation in user experiences. It is important to recognize that the impact of any behavior varies between people. In the case of smartphone use, the same usage may differ between users in perceived and actual functional impacts. Clearly, many users report at least some concerns with how they self-regulate their smartphone usage (Horwood \& Anglim, 2018), however it is unclear how problematic these experiences are, how they may be offset by the benefits people derive from smartphone use, and how the broader media coverage of "smartphone addiction" is impacting people's perceptions. Again, the lack of evidence beyond selfreport measures of problematic smartphone use is a limitation in the current literature.

\subsection{Self- and Other-Ratings of Problematic Smartphone Use}

Despite the recent surge in research on problematic smartphone use (for reviews see Elhai et al., 2017; Elhai, Levine, \& Hall, 2019), almost all research has relied on self-report assessment. In general, research has not yet converged on how best to define problematic smartphone use and "smartphone addiction", and many different measures have been developed (see review by Yu \& Sussman, 2020). It should be noted that a small number of studies have used objective smartphone use data (for a review, see Ryding \& Kuss, 2020), but this represents a somewhat different construct. For instance, Elhai et al (2018) used objective use data from participants' smartphones to determine levels of use over a one-week period. Also, Orben and Przybylski (2020) employed an online time-use diary method to assess teenager's smartphone use in real time. However, problematic smartphone use is not the same as objective use, whether it be quantity or type of use. It is the functional impact (e.g., health, well-being, relationships, 
productivity) and the sense of a lack of control which makes this type of use problematic.

Despite the potential for observer reports to provide fundamental insights into the nature of problematic smartphone use, to date, there have been almost no studies of problematic smartphone use that have employed other-rater assessments. One exception was a study that examined self- and parent-ratings in Korean adolescents (Youn et al., 2018). The authors found a correlation between parent and adolescent ratings of 'smartphone addiction' of $r=.47$. They also found parents rated their adolescent's smartphone use as more problematic than did the adolescents, whereby $21 \%$ of adolescent self-ratings were above the "at risk" cut-off compared to $40 \%$ of parentratings. Despite this one small study, there has been no large-sample comprehensive examination of self-other agreement on problematic smartphone use. In particular, findings based on the parent-child relationship may not generalise to either adults or other relationships types (e.g., friends, partners, siblings, etc.).

Given the paucity of research using other-ratings in the context of problematic smartphone use, it is helpful to examine research on other psychological constructs such as performance and personality. In terms of performance, self-other ratings are commonly used in organizational settings to assess the effectiveness of managers (e.g. see Brett \& Atwater, 2001; Markham, Markham, \& Smith, 2017), and whether managers see themselves in similar ways to how their staff see them. In terms of personality, a meta-analysis of the degree of agreement between self- and other-ratings of the Big Five found correlations ranging from .29 for agreeableness to .41 for extraversion (Connelly \& Ones, 2010). Other-ratings do not a guarantee objective measurement, and indeed have their own methodological limitations (Rogers, Wood, \& Furr, 2018), however they can help to determine if there are observable experiences (e.g. anxiety or low mood) or behaviors (e.g. long periods of screen-based absorption) associated with a proposed construct. Other-ratings also help to enable researchers to assess the degree to which self-report data is valid. They can be used to assess the degree to which common method bias, socially desirable responding, and poor recall impact ratings.

Although studies examining other constructs have found reasonable self-other agreement in the field of personality (e.g. H. Kim, Di Domenico, \& Connelly, 2019; Nuzum, Ready, \& Clark, 2019), and that other-ratings can add unique explanatory information to an assessment of a focal (Tornow, 1993), there are conditions that can enhance or degrade the quality of other-ratings. Valid other-ratings require that the focal behaves in a consistent manner across situations where trait perceptions might be formed (Kenrick \& Funder, 1988), and, other-raters must be able to accurately judge the observed behavior (Bernieri, Zuckerman, Koestner, \& Rosenthal, 1994). The accuracy of an other-rater's assessment of a focal is dependent on the other-rater having access to 'good information' about the focal (Funder, 1995), however the type of information available to an other-rater can be contingent on their relationship to the focal (Connelly \& Ones, 2010). For example, co-workers, spouses, and parents will typically have access to different information. Hence, to understand and interpret observer ratings for any construct, it is useful to compare self-other agreement as a function of rater characteristics. 
Research Question 1: To what extent do self- and others-ratings of problematic smartphone use agree, and to what extent does this agreement vary by rater type?

\subsection{Personality and Problematic Smartphone Use}

While the causes of problematic smartphone use are, as yet, unclear, a body of research has found that personality correlates strongly with self-reported problematic smartphone use (Blackwell, Leaman, Tramposch, Osborne, \& Liss, 2017; de Francisco Carvalho et al., 2018; Gao et al., 2017; Horwood \& Anglim, 2018; Hussain, Griffiths, \& Sheffield, 2017; Y. Kim et al., 2016; Roberts, Pullig, \& Manolis, 2015; Takao, 2014). In particular, of the Big Five (Anglim \& O’Connor, 2019; John \& Srivastava, 1999), high neuroticism and low conscientiousness are the strongest predictors of problematic smartphone use. The combination of high neuroticism and low conscientiousness is associated with many negative life outcomes including poorer health and well-being (Anglim, Horwood, Smillie, Marrero, \& Wood, 2020; Roberts, Jackson, Fayard, Edmonds, \& Meints, 2009). People high on neuroticism tend to experience more negative emotions, see the world through a lens of negativity, and engage in emotionfocused coping strategies (Barlow, Sauer-Zavala, Carl, Bullis, \& Ellard, 2014). People low on conscientiousness are less likely to delay gratification and tend to perform fewer health behaviors (e.g. maintaining a healthy weight or engaging in regular exercise) and more unhealthy activities (e.g. consuming alcohol or smoking tobacco) (Roberts et al., 2009). The cognitive and behavioral influences of high neuroticism and low conscientiousness on health outcomes appear to also extend to smartphone use.

Nonetheless, existing research on personality and problematic smartphone use has largely relied on self-report measures. One exception was the important study by Stachl et al. (2017) which correlated personality with objective patterns of smartphone use, although it was not focused on whether the use was problematic. As such, it is unclear whether the observed relationships between personality and problematic smartphone use are influenced by self-report biases or subjective neurotic tendencies. At present, it remains a possibility that the personality correlates of problematic smartphone use result from a tendency of high neuroticism people to worry about their health behaviors in the absence of any serious problems. If problematic smartphone use is no more than a dispositional tendency to worry about health behaviors generally, other-ratings of problematic smartphone use should be less strongly related to selfreport neuroticism. Alternatively, strong correlations between personality and otherratings of problematic smartphone use would strengthen the claim that dispositional tendencies influencing objective and observable behavior.

Research Question 2: What is the relationship between self-rated personality and other-rated problematic smartphone use, and how does the relationship differ from self-rated personality and problematic smartphone use?

\subsection{The Current Study}

The current study sought to contribute insights into self-other agreement of ratings of problematic smartphone use, and the relationship between personality and other-rated problematic smartphone use. Specifically, we obtained a large sample of university students who completed measures of personality (Big Five and HEXACO) and problematic smartphone use. Focal participants were then requested to nominate at least three other-raters who knew them well. The other-raters completed a measure of problematic smartphone use about the focal participant. 


\section{Method}

Data, analysis scripts, and study materials are available on the OSF at https://osf.io/k2t5h/?view only $=7468 \mathrm{cbcc} 49304 \mathrm{~b} 1 \mathrm{e} 9 \mathrm{c} 1 \mathrm{f} 7587508 \mathrm{c} 2309$

\subsection{Participants and Procedure}

Participants were undergraduate psychology students at an Australian university who consented for their data to be used for research purposes. Data collection took place between June and December 2019. Focal participants completed an online questionnaire that measured personality (i.e., Big Five and HEXACO), problematic smartphone use and several other measures that did not form part of the current study. At the end of the survey, focal participants were invited to nominate at least three other-raters. Otherraters then received an email asking them to complete a survey about the focal participant that included questions about the nature of their relationship with the focal, a measure of problematic smartphone use, and several measures that did not form part of this study. The study received ethics approval from the Faculty of Health Ethics Committee at the first author's university.

Several steps were undertaken to obtain the final sample. First, of the 1,415 focal participants who completed the study, 342 were omitted for one or more of the following reasons: (a) they attempted to answer more than 10 of the IPIP items in less than one second $(n=6)$, (b) their overall survey completion time suggested nonconscientious completion $(\mathrm{n}=3)$, (c) they gave the same response to all IPIP items ( $\mathrm{n}$ $=0)$, (d) they reported not using a smartphone $(\mathrm{n}=2)$, and (e) after excluding other raters that did not satisfy inclusion requirements, they had no other raters $(n=342)$. Second, of the 3,767 other raters, 1,222 were omitted for one or more of the following reasons: (a) they did not answer the question about their relationship with the focal $(\mathrm{n}=$ 117), (b) they completed the survey too quickly [defined as 3 seconds per item plus about 30 seconds of reading general instructions and corresponding to a slight break in the histogram of completion times] $(n=127)$, $(c)$ their focal participant was removed based on previously mentioned criteria $(n=14)$, $(d)$ they selected 'do not know' to 6 or more of the problematic smartphone usage items $(n=1039)$, (e) when asked about the degree to which they knew the focal participant, they indicated "not at all" or "not well" [acceptable response options were "reasonably well", "very well", or "extremely well"] $(\mathrm{n}=136)$, and (f) when asked about their knowledge of the focal's smartphone use, they indicated "not at all" or "not well" [acceptable response options were "reasonably well", "very well", or "extremely well"] $(\mathrm{n}=638)$.

The final sample consisted of 1,073 focal participants $(83 \%$ female; mean age $25.58, S D=8.65$ ) and 2,545 other-raters (mean number of other-raters was $2.37, S D=$ $1.05 ; 22.2 \%$ had $1,32.8 \%$ had $2,35.2 \%$ had 3 , and $6.8 \%$ had 4 , and $3.0 \%$ had 5 or more raters). The most common relationship of other-rater to focal participants was friend $(36.9 \%)$, parent $(24.5 \%)$, partner $(18.4 \%)$, and sibling $(12.5 \%)$. Of the other-raters, $33.0 \%$ lived in the same house as the focal participant. The mean number of years knowing the focal was 13.58 (median $=12, \mathrm{SD}=10.18$ ).

\subsection{Measures}

\subsubsection{Problematic Smartphone Use}

Problematic smartphone use was measured using the 21-item Adolescent Preoccupation with Screens Scale (Hunter et al., 2017), adapted for use with an adult 
sample. In two scale items, the term 'parents' was replaced with the words 'family or friends' (e.g. "My family or friends complain that I use my smartphone too much"). Items for the other-rater version of this scale were created by replacing first-person pronouns with generic third-person pronouns (e.g., "I use my smartphone to make myself feel better" became "They use their smartphone to make themselves feel better"; see OSF repository for full details). Items were rated on a scale where $1=$ strongly disagree, 2 = disagree, $3=$ neither agree nor disagree, $4=$ agree, and $5=$ strongly agree. This 5-point scale was chosen to facilitate a clear estimate of the degree of item endorsement as indicated by the percentage of participants indicating that they agree or strongly agree with the statement.

In the other-rating survey, participants were also given a "don't know" option. The overall score was the mean of the items. In the case of other-ratings, we allowed others to have up to 5 missing items before excluding the other-rater from the study. For other-raters with 1 to 5 missing responses, the overall mean was the mean of answered items. We obtained a problematic smartphone use self-rating, other-rating, and a combined other-rating. The other-rating was a single score for each other-rater, whereas the combined other-rating was the average of all available other-ratings for that focal. An exploratory factor analysis strongly supported the presence of one large global problematic smartphone use factor. However, there was some evidence for five highly correlated factors; so, in order to further probe the nuances of the measure we obtained scores for these subscales and labelled them absorption, addiction, escapism, online acceptance, and offline disruption. These factor analyses and scale descriptions are described in Section 3.1.

\subsubsection{Big Five Personality}

The Big Five personality factors were measured using the 50-item IPIP NEO (Goldberg, 1992) . Focal participants responded to items on a scale from $1=$ strongly disagree to $5=$ strongly agree. Scale scores were obtained as the mean of items after any necessary item reversal.

\subsubsection{HEXACO Personality}

The 100-item version of the HEXACO PI-R (Ashton, Lee, \& de Vries, 2014; K. Lee $\&$ Ashton, 2018) was used to measure the 6 domains and 25 facets of the HEXACO framework. Focal participants responded to items on a scale from $1=$ strongly disagree to $5=$ strongly agree. Scale scores were obtained as the mean of items after any necessary item reversal.

\subsection{Data Analytic Approach}

In order to examine differences between self- and other-raters of problematic smartphone use, we first conducted an analysis of the problematic smartphone use items. We used exploratory factor analysis to understand and compare the factor structure of self- and other-ratings. This allowed us also to identify five different aspects of problematic smartphone use, which provided a useful framework for organizing the items into thematic groups. It also permitted a more nuanced understanding of some of the correlations between personality and problematic smartphone use. To compare selfand other-ratings at the item-level, we examined differences in level of endorsement by comparing the percentage of self- and other-raters who endorsed each statement (i.e., by collapsing the "agree" and "strongly agree" item response options). We also 
examined self-other agreement at the item-level. This included self-other correlations using the full five-point range of the scale and Cohen's kappa using binary agreement (i.e., "agree" and "strongly agree" versus "neither agree nor disagree", "disagree", and "strongly disagree").

We then examined the correlations and mean differences for self and other ratings of overall problematic smartphone use. Note that many focal participants had more than one other-rater, and all analyses of self-other agreement, unless otherwise noted, utilized the other-rater sample (i.e., self-ratings are merged into the other-rater sample so that the other-raters becomes the unit of analysis). We compared the mean responses for self-ratings with those for other-ratings, and we also compared various types of other-raters (e.g. parents, friends, siblings) based on whether they cohabit with the focal participant, and the nature of their relationship with the focal participant. To quantify the degree of agreement between self- and other-ratings, we calculated the correlation between self- and other-raters for all other-raters and for the various types of other-raters. In order to assess whether self-raters were more or less accurate than other-raters, we compared the intercorrelations between self-ratings, cohabiting others, and non-cohabiting others for the subset of participants who had both types of otherraters.

We then examined the effect of rater type on the relationship between personality and problematic smartphone use. When estimating correlations and regression models of personality predicting problematic smartphone use, we included three versions of problematic smartphone use: (a) self-ratings, (b) other-ratings, and (c) combined other-ratings.

\section{Results}

\subsection{Problematic Smartphone Use Items}

We first sought to examine the factor structure of the problematic smartphone use items. The percentage of variance explained by the first 7 components was 38.2, 9.9, 6.5, 5.4, 4.3, 3.6, and 3.3 for self-report and 49.5, 7.8, 4.6, 3.8, 3.0, 2.8, and 2.5 for other-report. The variance explained shows how the factor structure for both self- and other-ratings had a very large first factor consistent with a general problematic smartphone use factor. It also shows that the size of this first factor was slightly larger for other-ratings, suggesting that self-raters had a more nuanced representation of their own smartphone use experience. Cronbach's alpha of overall problematic smartphone use ratings was .92 for self-ratings and .95 for other-ratings.

While not the primary focus of this research, we examined whether there was any evidence of subscale structure in the 21-item measure using exploratory factor analysis with maximum likelihood extraction and promax rotation with 1 to 7 factors. We found that extracting five factors most clearly illustrated the ways that items clustered (see Table 1). We provisionally labelled these factors absorption, addiction, escapism, online acceptance, and offline disruption. Absorption involved losing track of time and spending too much time using a smartphone. Addiction involved the experience of negative emotions when unable to use the smartphone and a "buzz" when using the smartphone. Escapism was concerned with using the smartphone to escape real life and alleviate loneliness. Online acceptance was the degree to which people felt more accepted by people online than in real life. Offline disruption captured the degree to which friends and family complained about the person's smartphone usage. This five 
factor solution provides a more granular view than the two-factor model emphasised by Hunter et al. (2017). Specifically, Hunter et al. (2017) identified a mood management factor which included addiction, escapism, and online acceptance items and a behavioral preoccupation factor which included absorption and offline disruption items. Cronbach's alphas for were .74 / .82 (escapism), .85 / .88 (addiction), .84 / .79 (online acceptance), $.87 / .90$ (absorption) and $.81 / .85$ (offline disruption) for self and other ratings respectively.

Table 1 presents for each item the percentage of self-raters endorsing the item, the percentage of other-raters endorsing the item, the item-total correlations for selfand other-ratings, and the correlation between self- and other-ratings. Endorsement was calculated as the percentage of people indicating that they agree or strongly agree with the item. Endorsement of absorption items was particularly high with more than half of the sample believing they spent too much time on their smartphone. About a third of the sample endorsed escapism items, whereas offline disruption and, particularly, online acceptance items were endorsed less. In general, other-raters endorsed the items less than self-raters, especially for absorption items. Consistent with the large first factor, item-total correlations were large for all items for both self- and other-ratings.

In general, self- and other-raters showed some level of agreement on individual items. The average item-level self-other correlation was .21. Item 18 (i.e., friends and family complaining about smartphone use) and Item 17 (i.e., going to bed late because of smartphone use) had slightly larger self-other correlations. This may be because these two items were more objective and observable. In contrast, Item 7 (i.e., the feeling of being somewhere else when using the smartphone) had the smallest self-other correlation, probably reflecting the subjectivity of this judgement and its lack of observability. Overall, the pattern of results suggests that problematic smartphone use is reasonably observable by others, albeit that others are less willing to judge other people's use as excessive, and the mental model of a person's smartphone use held by others is less nuanced.

\subsection{Means and Self-Other Agreement}

Reported levels of problematic smartphone use were higher for self-ratings $(M$ $=2.58, S D=0.69)$ than for other-ratings $(M=2.28, S D=0.88), d=0.37, p<.001$. The correlation between self-ratings and other-ratings was $r=.38, p<.001(n=2545)$. Consistent with reduced measurement error, when other-ratings were averaged for participants who had more than one other-rater, the correlation between self-ratings and combined other-rating increased to $r=.44, p<.001(n=1,073)$. To quantify the general level of agreement between other-raters, we calculated the intraclass correlation coefficient for all other-ratings (ICC1 $=.29 ; n=2545)$.

Table 2 presents the means, standard deviations and self-other correlations for problematic smartphone use by cohabitation status and relationship type. People who lived in the same house as the focal participant rated others as having slightly more problematic smartphone use than people who did not live in the same house as the focal. People who cohabited also appeared to be more accurate raters of problematic smartphone use as indicated by higher self-other agreement than non-cohabiting others ( $r=.44$ versus $r=.35$ ). Mean ratings of problematic smartphone use were fairly similar across relationship types. While there was some evidence that parents and partners 
showed greater self-other agreement than siblings and friends, this difference was not statistically significant.

In order to assess the relative accuracy of self- and other ratings, the following analysis was performed. First, data was extracted for all participants who had both a cohabiting other-rater and a non-cohabiting other-rater. This yielded 471 focal cases. Where these cases had more than one cohabiting other or more than one non-cohabiting other, one was selected at random. We then correlated problematic smartphone use ratings for these three types of (i.e., self, cohabiting other, non-cohabiting other). The correlations were .47 (self with cohabiting other), .38 (self with non-cohabiting other), and .32 (cohabiting other with non-cohabiting other). We also computed rater-total correlations where we omitted the rater of interest (e.g., correlating self-ratings with the average of cohabiting and noncohabiting others). The corrected rater-total correlations were .52 for self-ratings, .46 for cohabiting others, and .40 for non-cohabiting others. While other raters will vary in their degree of knowledge of the focal participant's smartphone use, the pattern of correlation generally shows that self-ratings are more accurate than cohabiting others and cohabiting others are more accurate than noncohabiting others.

\subsection{Personality and Problematic Smartphone Use}

Table 3 presents the correlation of demographics and personality domains with self- and other-rated problematic smartphone use (see online supplement for HEXACO facet correlations). Females and younger adults had higher levels of problematic smartphone use for both self-ratings and other-ratings. Given that gender and age are objective variables, there is no concern that common method variance would inflate correlations with self-rated problematic smartphone use, as may be the case with selfreported personality. As such, it is interesting to note that correlations with other-rated smartphone use is less than self-rated, although this reduction seems somewhat less for age than for gender.

For the Big Five, neuroticism $(r=.41)$ and conscientiousness $(r=-.36)$ were the strongest correlates of self-rated problematic smartphone use. Correlations for extraversion $(r=-.16)$, openness $(r=-.14)$ and agreeableness $(r=-.19)$ were significant but somewhat weaker. Consistent with neuroticism-related variance being distributed across multiple personality domains, correlations with HEXACO personality were less differentiated. In general, correlations between personality and other-rated personality exhibited a similar pattern, albeit correlations were about half the size of self-rated problematic smartphone use. The one exception was Big Five extraversion which showed a small to medium negative correlation with self-rated problematic smartphone use but a correlation close to zero with other-rated problematic smartphone use. Consistent with reducing measurement error, correlations between personality and combined other-ratings (i.e., where ratings for focals with more than one rater were averaged) were larger than those correlations with individual other-raters.

We also compared the current results to those of Horwood and Anglim (2018) who used a similar measure of the Big Five (300-item version rather than the 50 item) but a different measure of problematic smartphone use. In that study, Big Five correlations with self-reported problematic smartphone use were as follows: neuroticism .41, extraversion .00, openness -.15, agreeableness -.18, and conscientiousness -.38 . The main difference is that in the current study we obtained a 
small negative correlation between extraversion and self-reported problematic smartphone use. To better understand this difference, we examined the correlations between personality and self-report ratings of the different aspects of problematic smartphone use (see Table 5). In general, escapism $(r=-.21)$ and online acceptance $(r$ $=-.27$ ) correlated negatively with Big Five extraversion. A close examination of the items (as presented in Table 1) shows how they reflect a form of introversion: i.e., using the smartphone to deal with loneliness and forget about real life, and feeling closer to people in the online environment. These items were less prevalent in the measure of problematic smartphone use used in Horwood and Anglim (2018).

Finally, regression models were estimated predicting problematic smartphone use from Big Five (Table 6) personality (see online supplement for corresponding HEXACO regression). In general, regression models explained substantially more variance in self-rated problematic smartphone use than other-rated problematic smartphone use. The main difference in the pattern of coefficients was that extraversion was a significant predictor of other-rated problematic smartphone use, but not self-rated problematic smartphone use. In comparison to the zero-order correlations, agreeableness is a significant negative correlate but not a significant coefficient, and extraversion is negatively related (self-report) or uncorrelated (other-report) in bivariate analysis but has a positive coefficient in the regression model. In sum, it seems likely that once the overlap of extraversion and agreeableness with neuroticism is accounted for, these coefficients change. Extraversion may become a purer measure of sociability rather than positive and negative mood.

\section{Discussion}

The current study aimed to contribute insights into self-other agreement of ratings of problematic smartphone use, and the relationship between personality and other-rated problematic smartphone use. Several important findings emerged. First, other-ratings of problematic smartphone use were moderately correlated with selfratings of problematic smartphone use suggesting that problematic smartphone use is an observable construct. Second, the pattern of self-other agreement suggested that selfratings were the most accurate assessment of problematic smartphone use, followed by cohabiting others and finally non-cohabiting others. Third, people rated their own smartphone use as more problematic than did others. Fourth, there was minimal effect of relationship type on the degree to which smartphone use was perceived to be problematic, although other-raters who cohabitated with the focal rated problematic smartphone use higher than non-cohabitating others. Fifth, replicating existing research (Horwood \& Anglim, 2018), higher neuroticism and lower conscientiousness predicted more self-rated problematic smartphone use. Finally, the relationship between personality and other-rated problematic smartphone use showed the same pattern of correlations as self-rated problematic smartphone use, albeit with a reduced magnitude. Findings have implications for understanding the nature of problematic smartphone use and the role of personality.

\subsection{Self- and Other-Ratings of Problematic Smartphone Use}

Our results suggest that individual differences in problematic smartphone use are observable. Other-raters were able to reliably and consistently rate problematic smartphone use in focals, suggesting that there are real and objective individual differences in problematic smartphone use. This suggests that such ratings and not 
simply social perceptions about the dangers of new technology or a general tendency for neurotic people to worry about things (Anderson \& Rainie, 2018; Orben, 2020). This is primarily evidenced by the strong self-other agreement for problematic smartphone use $(r=.38)$. The only other study in this area, to our knowledge, correlated parent and adolescent ratings of adolescent "smartphone addiction" (Youn et al., 2018). They obtained a correlation of $r=.47$, which is similar to what we obtained for cohabitating others (i.e., $r=.44$ ). The level of agreement is also similar to that seen for personality traits (Connelly \& Ones, 2010) and larger than typically seen for job performance (Conway \& Huffcutt, 1997). It is also similar to the correlation between self-rated problematic smartphone use and objective measures of daily screen time (e.g., $r$ between .30 and .40, Ellis, Davidson, Shaw, \& Geyer, 2019).

We found that people were better at rating their own problematic smartphone use than were others, and that of the others, people who lived together were better raters than those who did not. While some research suggests that close others may be just as accurate as focal raters at rating common daily activities (Vazire \& Mehl, 2008), this did not appear to be the case for problematic smartphone use. These results are consistent with theories (Funder, 1995; Nuzum et al., 2019) that validity and self-other agreement is directly related to the amount of relevant information possessed by the rater (Connelly \& Ones, 2010; Vazire \& Mehl, 2008). In the case of problematic smartphone use, there is the extent to which a rater is able to observe a person's smartphone use in a variety of contexts and situations over time. People who cohabit will have greater knowledge of how someone uses their smartphone in the home environment. This includes the extent to which habitual smartphone use forms part of their daily home routine. Beyond observing use, problematic smartphone use is also concerned with subjective attitudes and beliefs about smartphone use, such as anxiety when not checking the phone, feeling like use is out of control, and feeling like use is negatively impacting other aspects of life. In general, people have privileged access to their own thoughts on these matters. While they may share these thoughts with others or convey these concerns indirectly, this asymmetry of information may partially explain why self-ratings were more valid. This point is supported by the finding that items concerned with more observable behaviors (e.g., smartphones influencing when a person goes to bed or smartphone use causing interpersonal conflict) had a higher degree of self-other agreement than did items that were more internal (e.g., the subjective experience of using a smartphone).

We also found that people rated their own use as more problematic than did other raters. There are several possible explanations for this. First, there may be social norms that lead others to be 'kind' to the person they are rating. In the present study, most other-raters were friends or family, as opposed to more formal relations, such as co-workers. Other-raters may have wanted to avoid reporting something negative about a person they care for (Connelly \& Ones, 2010); in contrast, it may be more normatively acceptable and humble for people to admit their own minor flaws (e.g., I use my smartphone too much). Second, the high rate of self-reported problematic smartphone use might also be influenced by the increasingly wide-spread media coverage of 'smartphone addiction' (De-Sola Gutiérrez, Rodríguez de Fonseca, \& Rubio, 2016; Orben, 2020), the most recent iteration of the collective concern that technology is bad 
for our health and wellbeing. This might serve to amplify concerns generally, but particularly for the self-ratings.

Interestingly, perceptions of problematic smartphone use varied little across types of raters and did not reflect social stereotypes about who might disapprove of smartphone use. For example, the stereotypes that parents are particularly concerned about their children's smartphone use, or that older people are less tolerant of novel technology, were not evident in the present study. This differs from Youn et al. (2018) where parents rated their adolescent's smartphone use as more problematic than did the adolescents. That said, our study involved young adults, and parents may be less aware and less concerned about smartphone use once children reach adulthood. Similarly, an expectation that younger cohorts, who have had the same social and cultural exposure to smartphone technology, will be more accepting of smartphone use behaviors among their peers was also not evident. Friends of focals did not rate focal problematic smartphone use more or less severely than other rater types, indicating that there were no clear cohort effects.

The question of whether problematic smartphone use is a real or imagined construct is, in part, based in unsuccessful attempts to define problematic use in quantifiable terms (Ellis et al., 2019; Wilcockson, Ellis, \& Shaw, 2018). There seems to be no threshold to cross, or style of use to engage in, that is universally problematic for every person. Previous studies that have used objective measures of the quantity and type of smartphone use (Elhai et al., 2018; Orben \& Przybylski, 2020) reflect a distinct but related construct to problematic smartphone use. It seems that rater judgement is required to measure the functional and emotional impact of that use. Our findings that self- and other-ratings agree suggest that at least some aspect of problematic smartphone use is observable by others. However, it is important to recognize that people tend to associate with others who confirm their self-perceptions (H. Kim et al., 2019), an effect that can influence how focals decide who to nominate as raters (Leising, Erbs, \& Fritz, 2010). For example, if users believe the social hype that 'new technology must be bad for our health' and believe they use their smartphone too much, their belief could become a self-fulfilling prophesy. That is, if the belief informs the user's behaviors (persistent checking) and narrative (e.g. 'I need to stop using my phone so much'), other-raters may observe the focal's own manifest anxieties or beliefs about their smartphone use, rather than behaviors or beliefs that are truly a symptom of problematic use.

Finally, it is important to consider the possible cognitions or motives behind other-rater judgement. Where items call for a subjective assessment, it is reasonable to presume that other-raters are applying their own standards to the questions. For example, the question 'I spend too much time on my smartphone' requires the rater to apply their own judgement for what constitutes 'too much'. However, when an otherrater answers the same question about the focal, they are likely to apply their own threshold for 'too much', which may be quite different to that of the focal. In other cases, other raters may apply heuristics such as focusing on preoccupation and amount of use rather than functional consequences. Similarly, other-raters might focus on instances when the focal's smartphone use irritates the rater. If that were the case, otherratings become less of an assessment that the focal's use is problematic for the focal, and more a reflection that the focal's use is perceived as problematic for the rater. 


\subsection{Personality and problematic smartphone use}

The study also contributes substantially to an understanding of how individual differences in personality can explain problematic smartphone use. Before discussing the correlations with other-rated problematic smartphone use, we note that the correlations with self-rated problematic smartphone use largely replicates past research (e.g. Horwood \& Anglim, 2018; Pearson \& Hussain, 2015; Stachl et al., 2017). Specifically, Big Five neuroticism (-) and conscientiousness $(+)$ were moderate to strong correlates of problematic smartphone use; and the HEXACO correlations also showed a similar pattern, albeit neuroticism is distributed across several domains of the HEXACO model (e.g., high emotionality, low honest-humility). The only small difference with past research is the negative correlation between Big Five extraversion and self-rated problematic smartphone use. Some research has obtained a correlation that is close to zero or even slightly positive for extraversion. In general, it appears that the correlation with extraversion depends on the nature of the scale measuring problematic smartphone use. In the current study, the measure included items measuring feelings of greater acceptance in online communities and escapist behavior indicative of introversion. In contrast, where scales include more items measuring smartphone use for social purposes (e.g., messaging and phone calls with friends), a positive correlation or no correlation with extraversion would be expected.

However, the more important contribution of this study was to be the first to show how personality is related to other ratings of problematic smartphone use. We found that the pattern of correlations with personality is the same whether problematic use is measured using self-report or other-report, but the correlations are approximately half the magnitude when measured using other-report. Finding the same robust pattern of correlations suggests that the relationship between personality and problematic smartphone use is real and not merely a function of common method variance or a neurotic self-rater bias. Theoretically, the pattern of personality correlates could have differed for other-ratings. For instance, the effects of conscientiousness might have been more observable (e.g. going to bed too late) than neuroticism (e.g. feeling anxious). However, these differential correlates of personality with problematic smartphone use did not arise. It may be that the personality-related effect on problematic smartphone use is similarly visible across traits. For instance, displaying anxiety in relation to smartphone use may be visible in some contexts. Alternatively, it may be that personality has a holistic effect on smartphone use, and it is this use which is observed.

It is also unsurprising that other-ratings correlate about half as much with problematic smartphone use. Our two main explanations are greater validity of selfratings and common method bias. First, as we have discussed, we found that self-ratings are more valid than cohabiting others, and cohabiting others are more valid than noncohabiting others. This reduced validity of measurement for other ratings will attenuate the correlations. Of course, combining multiple other raters will increase the reliability of measurement and increase correlations between personality and other ratings, and this is what we found. Second, common method bias will inflate correlations between self-rated personality and self-rated problematic smartphone use. This bias includes a wide range of measurement biases (e.g., extreme responding, social desirability bias). It also includes the underlying concept that people perceive their personality in a certain way, and they perceive themselves on the criteria in a certain way. This underlying 
mental model may increase the correlations between traits and criteria. For example, a person may see themselves as neurotic and see themselves as getting anxious when they are without their phone. Both perceptions of personality and criteria may deviate from the truth in ways that inflate correlations. So, in summary, the true correlations between personality and problematic smartphone use may be somewhere in between those obtained for self-report and other-report ratings.

\subsection{Limitations and Future Research}

Several limitations and opportunities for future research should be noted. First, it would be useful for future research to also examine objective measurements of problematic smartphone use in combination with self- and other-ratings. While there has been some work examining objective measurement, more work is needed to move beyond simple measures such as hours per day of screen time or number of handset pickups. Second, future research could investigate the influence of rater characteristics and beliefs on how others perceive problematic smartphone use in others. This could examine the degree to which perceptions reflect the behavior of the rated individual as opposed to the beliefs held by the rater about appropriate use. Finally, we note that focals selected their own other-raters which may lead to slightly more positive ratings of the focal (Funder \& Randall, 1991; Leising et al., 2010) than had raters been independent observers.

\subsection{Conclusion}

The current study contributes to the overall understanding of the nature of problematic smartphone use and its relationship with personality. By obtaining a large sample of self- and other-raters, we were able to address a fundamental criticism of the literature on problematic smartphone use. A major contribution of the present study is the examination of how self-rated personality predicts other-rated problematic smartphone use, and what level of agreement exists between self- and other-ratings of problematic smartphone use. The findings indicated that there is reasonable agreement between self- and other-rated problematic smartphone use, and that personality predicts other-rated problematic smartphone use. The results also contribute to the debate about whether problematic smartphone use is an observable construct or simply an artefact of societal concerns about technology or general neurotic tendencies. The self- and otherrater agreement suggests that there are aspects of problematic smartphone use that are objective and observable by others.

\section{References}

Anderson, J., \& Rainie, L. (2018). The Future of Well-Being in a Tech-Saturated World. Retrieved from https://www.pewresearch.org/internet/2018/04/17/the-future-of-well-being-in-a-tech-saturated-world/

Anglim, J., Horwood, S., Smillie, L., Marrero, R., \& Wood, J. (2020). Predicting psychological and subjective well-being from personality: A meta-analysis. Psychological Bulletin. doi:10.1037/bul0000226

Anglim, J., \& O'Connor, P. (2019). Measurement and research using the Big Five, HEXACO, and narrow traits: A primer for researchers and practitioners. Australian Journal of Psychology, 71(1), 16-25. doi:10.1111/ajpy.12202

Ashton, M., Lee, K., \& de Vries, R. E. (2014). The HEXACO Honesty-Humility, Agreeableness, and Emotionality factors: a review of research and theory. Personality and Social Psychology Review, 18, 139-152. doi:10.1177/1088868314523838

Barlow, D. H., Sauer-Zavala, S., Carl, J. R., Bullis, J. R., \& Ellard, K. K. (2014). The nature, diagnosis, and treatment of neuroticism: Back to the future. 2(3), 344-365. doi:10.1177/2167702613505532

Bernieri, F. J., Zuckerman, M., Koestner, R., \& Rosenthal, R. (1994). Measuring person perception accuracy: Another look at selfother agreement. Personality and Social Psychology Bulletin, 20(4), 367-378. doi:10.1177/0146167294204004 
Billieux, J., Maurage, P., Lopez-Fernandez, O., Kuss, D. J., \& Griffiths, M. D. (2015). Can disordered mobile phone use be considered a behavioral addiction? An update on current evidence and a comprehensive model for future research. Current Addiction Reports, 2(2), 156-162.

Billieux, J., Philippot, P., Schmid, C., Maurage, P., De Mol, J., \& Van der Linden, M. (2015). Is dysfunctional use of the mobile phone a behavioural addiction? confronting symptom - based versus process - based approaches. Clinical Psychology \& Psychotherapy, 22(5), 460-468.

Blackwell, D., Leaman, C., Tramposch, R., Osborne, C., \& Liss, M. (2017). Extraversion, neuroticism, attachment style and fear of missing out as predictors of social media use and addiction. J Personality \& Individual Differences, 116, 69-72. doi:10.1016/j.paid.2017.04.039

Blass, E. M., Anderson, D. R., Kirkorian, H. L., Pempek, T. A., Price, I., \& Koleini, M. F. (2006). On the road to obesity: Television viewing increases intake of high-density foods. Physiology and Behavior, 88(4-5), 597-604.

Brett, J. F., \& Atwater, L. E. (2001). $360^{\circ}$ feedback: Accuracy, reactions, and perceptions of usefulness. Journal of Applied Psychology, 86(5), 930. doi:10.1037//0021-9010.86.5.930

Chen, C., Zhang, K., Gong, X., Zhao, S., Lee, M., \& Liang, L. (2017). Understanding compulsive smartphone use: An empirical test of a flow-based model. International Journal of Information Management, 37(5), 438-454. doi:https://doi.org/10.1016/j.ijinfomgt.2017.04.009

Cho, H.-Y., Kim, D. J., \& Park, J. W. (2017). Stress and adult smartphone addiction: Mediation by self-control, neuroticism, and extraversion. 33(5), 624-630. doi:10.1002/smi.2749

Connelly, B. S., \& Ones, D. S. (2010). An other perspective on personality: Meta-analytic integration of observers' accuracy and predictive validity. Psychological Bulletin, 136(6), 1092-1122. doi:10.1037/a0021212

Conway, J. M., \& Huffcutt, A. I. (1997). Psychometric Properties of Multisource Performance Ratings: A meta-Analysis of Subordinate, Supervisor, Peer, and Self-Ratings. Human Performance, 10(4), 331-360. doi:10.1207/s15327043hup1004_2

Csibi, S., Griffiths, M. D., Demetrovics, Z., \& Szabo, A. (2019). Analysis of Problematic Smartphone Use Across Different Age Groups within the 'Components Model of Addiction'. International Journal of Mental Health and Addiction, 1-16.

De-Sola Gutiérrez, J., Rodríguez de Fonseca, F., \& Rubio, G. (2016). Cell-Phone Addiction: A Review. Frontiers in Psychiatry, 7, 175-175. doi:10.3389/fpsyt.2016.00175

de Francisco Carvalho, L., Sette, C. P., \& Ferrari, B. L. (2018). Problematic smartphone use relationship with pathological personality traits: Systematic review and meta-analysis. Cyberpsychology, 12(3), 13-32. doi:10.5817/CP2018-3-5

Elhai, J., Dvorak, R. D., Levine, J. C., \& Hall, B. J. (2017). Problematic smartphone use: A conceptual overview and systematic review of relations with anxiety and depression psychopathology. Journal of Affective Disorders, 207, 251-259. doi:10.1016/j.jad.2016.08.030

Elhai, J., Levine, J. C., \& Hall, B. J. (2019). Problematic smartphone use and mental health problems: Current state of research and future directions. Dusunen Adam, 32(1), 1-3. doi:10.14744/DAJPNS.2019.00001

Elhai, J., Rozgonjuk, D., Yildirim, C., Alghraibeh, A. M., \& Alafnan, A. A. (2019). Worry and anger are associated with latent classes of problematic smartphone use severity among college students. Journal of Affective Disorders, 246, 209-216. doi:https://doi.org/10.1016/j.jad.2018.12.047

Elhai, J., Tiamiyu, M., Weeks, J., Levine, J., Picard, K., \& Hall, B. (2018). Depression and emotion regulation predict objective smartphone use measured over one week. Personality and Individual Differences, 133, 21-28. doi:https://doi.org/10.1016/j.paid.2017.04.051

Ellis, D. A., Davidson, B. I., Shaw, H., \& Geyer, K. (2019). Do smartphone usage scales predict behavior? International Journal of Human-Computer Studies, 130, 86-92. doi:10.1016/j.ijhcs.2019.05.004

Ellis, D. A., Kaye, L. K., Wilcockson, T. D. W., \& Ryding, F. C. (2018). Digital Traces of Behaviour Within Addiction: Response to Griffiths (2017). International Journal of Mental Health and Addiction, 16(1), 240-245. doi:10.1007/s11469-0179855-7

Funder, D. (1995). On the accuracy of personality judgment: A realistic approach. Psychological review, 102(4), 652-670. doi:10.1037/0033-295X.102.4.652

Funder, D., \& Randall, C. C. (1991). Explorations in Behavioral Consistency: Properties of Persons, Situations, and Behaviors. Journal of Personality \& Social Psychology, 60(5), 773. doi:10.1037/0022-3514.60.5.773

Gao, T., Xiang, Y.-T., Zhang, H., Zhang, Z., \& Mei, S. (2017). Neuroticism and quality of life: Multiple mediating effects of smartphone addiction and depression. Psychiatry Research, 258, 457-461. doi:https://doi.org/10.1016/j.psychres.2017.08.074

Goldberg, L. (1992). The development of markers for the Big-Five factor structure. Psychological Assessment, 4(1), 26. doi:10.1037/1040-3590.4.1.26

Herrero, J., Urueña, A., Torres, A., \& Hidalgo, A. (2019). Socially Connected but Still Isolated: Smartphone Addiction Decreases Social Support Over Time. 37(1), 73-88. doi:10.1177/0894439317742611

Horwood, S., \& Anglim, J. (2018). Personality and problematic smartphone use: A facet-level analysis using the Five Factor Model and HEXACO frameworks. Computers in Human Behavior, 85, 349-359. doi:https://doi.org/10.1016/j.chb.2018.04.013

Horwood, S., \& Anglim, J. (2019). Problematic smartphone usage and subjective and psychological well-being. Computers in Human Behavior, 97, 44-50. doi:10.1016/j.chb.2019.02.028

Hughes, N., \& Burke, J. (2018). Sleeping with the frenemy: How restricting 'bedroom use' of smartphones impacts happiness and wellbeing. Computers in Human Behavior, 85, 236-244. doi:https://doi.org/10.1016/j.chb.2018.03.047 
Hunter, S. C., Houghton, S., Zadow, C., Rosenberg, M., Wood, L., Shilton, T., \& Lawrence, D. (2017). Development of the Adolescent Preoccupation with Screens Scale. BMC public health, 17(1), 652. doi:10.1186/s12889-017-4657-1

Hussain, Z., Griffiths, M. D., \& Sheffield, D. (2017). An investigation into problematic smartphone use: The role of narcissism, anxiety, and personality factors. Journal of Behavioral Addictions, 6(3), 378-386. doi:10.1556/2006.6.2017.052

$\mathrm{Ihm}$, J. (2018). Social implications of children's smartphone addiction: The role of support networks and social engagement. Journal of Behavioral Addictions, 7, 473+. Retrieved from http://link.galegroup.com.ezproxyb.deakin.edu.au/apps/doc/A546621281/AONE?u=deakin\&sid=AONE\&xid=3dc84196

Ismaeel, F. T. (2019). The Impact of Smart Phones on Musculoskeletal Pain on Students in Tikrit University. Indian Journal of Public Health Research \& Development, 10(7), 553-557. doi:10.5958/0976-5506.2019.01629.2

John, O. P., \& Srivastava, S. (1999). The Big Five trait taxonomy: History, measurement, and theoretical perspectives. Handbook of personality: Theory and research, 2(1999), 102-138.

Kenney, E. L., \& Gortmaker, S. L. (2017). United States adolescents' television, computer, videogame, smartphone, and tablet use: associations with sugary drinks, sleep, physical activity, and obesity. The Journal of pediatrics, 182, 144-149.

Kenrick, D. T., \& Funder, D. C. (1988). Profiting from controversy: Lessons from the person-situation debate. American Psychologist, 43(1), 23. doi:10.1037/0003-066X.43.1.23

Kim, H., Di Domenico, S. I., \& Connelly, B. S. (2019). Self-other agreement in personality reports: A meta-analytic comparison of self-and informant-report means. Psychological Science, 30(1), 129-138. doi:10.1177/0956797618810000

Kim, H., Min, J., Min, K., Lee, T., \& Yoo, S. (2018). Relationship among family environment, self-control, friendship quality, and adolescents' smartphone addiction in South Korea: Findings from nationwide data. PloS one, 13(2), e0190896-e0190896. doi:10.1371/journal.pone.0190896

Kim, Y.-J., Jang, H. M., Lee, Y., Lee, D., \& Kim, D.-J. (2018). Effects of Internet and Smartphone Addictions on Depression and Anxiety Based on Propensity Score Matching Analysis. International journal of environmental research and public health, 15(5). doi:10.3390/ijerph15050859

Kim, Y., Jeong, J. E., Cho, H., Jung, D. J., Kwak, M., Rho, M. J., Choi, I. Y. (2016). Personality factors predicting smartphone addiction predisposition: Behavioral Inhibition and Activation Systems, Impulsivity, and Self-Control. PloS one, 11(8). doi:10.1371/journal.pone.0159788

Lee, C., \& Lee, S.-J. (2017). Prevalence and predictors of smartphone addiction proneness among Korean adolescents. Children and Youth Services Review, 77, 10-17. doi:10.1016/j.childyouth.2017.04.002

Lee, K., \& Ashton, M. C. (2018). Psychometric properties of the HEXACO-100. Assessment, 25, 543-556.

Lee, Y., Chang, C., Lin, Y., \& Cheng, Z. (2014). The dark side of smartphone usage: Psychological traits, compulsive behavior and technostress. Computers in Human Behavior, 31, 373-383. doi:https://doi.org/10.1016/j.chb.2013.10.047

Leising, D., Erbs, J., \& Fritz, U. (2010). The letter of recommendation effect in informant ratings of personality. $98(4)$, 668. doi:10.1037/a0018771

Li, J., Lepp, A., \& Barkley, J. E. (2015). Locus of control and cell phone use: Implications for sleep quality, academic performance, and subjective well-being. Computers in Human Behavior, 52, 450-457. doi:https://doi.org/10.1016/j.chb.2015.06.021

Long, J., Liu, T.-Q., Liao, Y.-H., Qi, C., He, H.-Y., Chen, S.-B., \& Billieux, J. (2016). Prevalence and correlates of problematic smartphone use in a large random sample of Chinese undergraduates. BMC Psychiatry, 16(1), 408. doi:10.1186/s12888016-1083-3

Lowry, R., Wechsler, H., Galuska, D. A., Fulton, J. E., \& Kann, L. (2002). Television viewing and its associations with overweight, sedentary lifestyle, and insufficient consumption of fruits and vegetables among US high school students: differences by race, ethnicity, and gender. Journal of School Health, 72(10), 413-421. doi:10.1111/j.1746-1561.2002.tb03551.x

Markham, S. E., Markham, I. S., \& Smith, J. W. (2017). A review, analysis, and extension of peer-leader feedback agreement: Contrasting group aggregate agreement vs. self-other agreement using entity analytics and visualization. The Leadership Quarterly, 28(1), 153-177. doi:10.1016/j.leaqua.2016.10.001

Namwongsa, S., Puntumetakul, R., Neubert, M. S., \& Boucaut, R. (2018). Factors associated with neck disorders among university student smartphone users. Work, 61(3), 367-378. doi:10.3233/WOR-182819

Nishida, T., Tamura, H., \& Sakakibara, H. (2019). The association of smartphone use and depression in Japanese adolescents. Psychiatry Research, 273, 523-527. doi:https://doi.org/10.1016/j.psychres.2019.01.074

Nuzum, H., Ready, R. E., \& Clark, L. A. (2019). Comparability of self- and other-rated personality structure. Psychological Assessment, 31(6), 741-750. doi:10.1037/pas0000696

Orben, A. (2020). The Sisyphean Cycle of Technology Panics.

Orben, A., \& Przybylski, A. K. (2020). Teenage sleep and technology engagement across the week. PeerJ. doi:10.7717/peerj.8427

Panova, T., \& Carbonell, X. (2018). Is smartphone addiction really an addiction? Journal Of Behavioral Addictions, 7, 252+. Retrieved from http://link.galegroup.com.ezproxyb.deakin.edu.au/apps/doc/A546621258/AONE?u=deakin\&sid=AONE\&xid=6423c3ee

Pearson, C., \& Hussain, Z. (2015). Smartphone use, addiction, narcissism, and personality: A mixed methods investigation. International Journal of Cyber Behavior, Psychology and Learning, 5(1), 17-32. doi:10.4018/ijcbpl.2015010102

Pew Research Centre. (2019). Smartphone ownership in advanced economies higher than in emerging. Retrieved from https://www.pewresearch.org/global/2019/02/05/smartphone-ownership-is-growing-rapidly-around-the-world-but-notalways-equally/pg global-technology-use-2018 2019-02-05 0-01/

Roberts, B. W., Jackson, J. J., Fayard, J. V., Edmonds, G., \& Meints, J. (2009). Conscientiousness. In M. R. Leary \& R. H. Hoyle (Eds.), Handbook of individual differences in social behavior (pp. 369-381): The Guilford Press. 
Roberts, J. A., Pullig, C., \& Manolis, C. (2015). I need my smartphone: A hierarchical model of personality and cell-phone addiction. Personality and Individual Differences, 79, 13-19. doi:10.1016/j.paid.2015.01.049

Rogers, K., Wood, D., \& Furr, R. (2018). Assessment of similarity and self-other agreement in dyadic relationships: A guide to best practices. Journal of Social Personal Relationships, 35(1), 112-134. doi:10.1177/0265407517712615

Rotondi, V., Stanca, L., \& Tomasuolo, M. (2017). Connecting alone: Smartphone use, quality of social interactions and well-being. Journal of Economic Psychology, 63, 17-26. doi:https://doi.org/10.1016/j.joep.2017.09.001

Ryding, F. C., \& Kuss, D. J. (2020). Passive objective measures in the assessment of problematic smartphone use: A systematic review. Addictive Behaviors Reports. doi:10.1016/j.abrep.2020.100257

Schweizer, A., Berchtold, A., Barrense-Dias, Y., Akre, C., \& Suris, J.-C. (2017). Adolescents with a smartphone sleep less than their peers. European Journal of Pediatrics, 176(1), 131-136. doi:10.1007/s00431-016-2823-6

Sohn, S., Rees, P., Wildridge, B., Kalk, N., \& Carter, B. (2019). Prevalence of problematic smartphone usage and associated mental health outcomes amongst children and young people: a systematic review, meta-analysis and GRADE of the evidence. BMC Psychiatry, 19(1). doi:10.1186/s12888-019-2350-x

Stachl, C., Hilbert, S., Au, J. Q., Buschek, D., De Luca, A., Bischl, B., Bühner, M. (2017). Personality Traits Predict Smartphone Usage. European Journal of Personality. doi:10.1002/per.2113

Tahir, M. J., Willett, W., \& Forman, M. R. (2019). The association of television viewing in childhood with overweight and obesity throughout the life course. American Journal of Epidemiology, 188(2), 282-293.

Takao, M. (2014). Problematic mobile phone use and big-five personality domains. Indian Journal of Community Medicine, 39(2), 111-113. doi:10.4103/0970-0218.132736

Tornow, W. W. (1993). Perceptions or reality: Is multi - perspective measurement a means or an end? J Human Resource Management, 32(2 - 3), 221-229. doi:10.1002/hrm.3930320203

van de Mortel, T. F. (2008). Faking it: social desirability response bias in self-report research. Australian Journal of Advanced $\begin{array}{llll}\text { Nursing, } & \text { 25(4), } & \text { Retrieved } & \text { from }\end{array}$ http://ezproxy.deakin.edu.au/login?url=http://search.ebscohost.com/login.aspx?direct=true \&db=ccm\&AN=105787183 \&site $=$ eds-live $\&$ scope $=$ site

Vandewater, E. A., Shim, M.-s., \& Caplovitz, A. (2004). Linking obesity and activity level with children's television and video game use. Journal of Adolescence, 27, 71-85. doi:10.1016/j.adolescence.2003.10.003

Vazire, S., \& Mehl, M. R. (2008). Knowing me, knowing you: the accuracy and unique predictive validity of self-ratings and otherratings of daily behavior. Journal of Personality and Social Psychology, 95(5), 1202. doi:10.1037/a0013314

Wilcockson, T., Ellis, D. A., \& Shaw, H. (2018). Determining typical smartphone usage: What data do we need? Cyberpsychology, Behavior, and Social Networking, 21(6), 395-398. doi:10.1089/cyber.2017.0652

Wolniewicz, C. A., Tiamiyu, M. F., Weeks, J. W., \& Elhai, J. (2018). Problematic smartphone use and relations with negative affect, fear of missing out, and fear of negative and positive evaluation. Psychiatry Research, 262, 618-623. doi:https://doi.org/10.1016/j.psychres.2017.09.058

Yang, J., Fu, X., Liao, X., \& Li, Y. (2020). Association of problematic smartphone use with poor sleep quality, depression, and anxiety: A systematic review and meta-analysis. Psychiatry Research, 284. doi:10.1016/j.psychres.2019.112686

Youn, H., Lee, S., Lee, S., Kim, J., Kim, J., Park, E., Lee, Y. (2018). Exploring the differences between adolescents' and parents' ratings on adolescents' smartphone addiction. Journal of Korean medical science, 33(52). doi: $10.3346 / \mathrm{jkms} .2018 .33 . \mathrm{e} 347$

Yu, S., \& Sussman, S. (2020). Does smartphone addiction fall on a continuum of addictive behaviors? International Journal of Environmental Research and Public Health, 17(2). doi:10.3390/ijerph17020422 
Table 1

Descriptive Statistics for Problematic Smartphone Usage Items

\begin{tabular}{|c|c|c|c|c|c|c|}
\hline \multirow[b]{2}{*}{ Item Text } & \multicolumn{2}{|c|}{$\begin{array}{l}\text { Item Endorsement } \\
\%\end{array}$} & Iter & tal $r$ & \multirow[t]{2}{*}{$\begin{array}{l}\text { Self- } \\
\text { other } \\
r\end{array}$} & \multirow[t]{2}{*}{$\begin{array}{l}\text { Self- } \\
\text { Other } \\
\text { Kappa }\end{array}$} \\
\hline & Self & Other & Self & Other & & \\
\hline \multicolumn{7}{|l|}{ Absorption } \\
\hline $\begin{array}{l}\text { 14. I spend too much time on my smartphone. } \\
\text { 15. I find myself thinking or saying "just a few more minutes" }\end{array}$ & 65 & 28 & .69 & .79 & .26 & .14 \\
\hline when using my smartphone. & 54 & 25 & .67 & .75 & .23 & .15 \\
\hline 16. I stay on my smartphone longer than I mean to. & 73 & 40 & .64 & .76 & .25 & .15 \\
\hline 17. I go to bed late because I have been using my smartphone. & 59 & 40 & .63 & .69 & .32 & .22 \\
\hline $\begin{array}{l}\text { 20. I lose track of time when I am using my smartphone. } \\
\text { 21. I use my smartphone even if I have more important things }\end{array}$ & 68 & 40 & .66 & .73 & .24 & .14 \\
\hline to do & 62 & 35 & .64 & .73 & .27 & .19 \\
\hline \multicolumn{7}{|l|}{ Addiction } \\
\hline $\begin{array}{l}\text { 3. When I try to reduce my smartphone use I feel anxious } \\
\text { (worried). } \\
\text { 4. When I am not using my smartphone, I keep thinking about }\end{array}$ & 14 & 12 & .66 & .73 & .21 & .14 \\
\hline it. & 12 & 11 & .65 & .76 & 19 & .09 \\
\hline 6. I feel bad when I cannot use my smartphone. & 17 & 17 & .65 & .74 & .23 & .17 \\
\hline 9. When I can't use my smartphone I get restless or irritable. & 19 & 15 & .67 & .73 & .20 & .13 \\
\hline 10. I feel most pleasure when using my smartphone. & 10 & 16 & 60 & .69 & .19 & .07 \\
\hline 12. I feel a buzz of excitement when on my smartphone. & 19 & 26 & .64 & .73 & .20 & .12 \\
\hline \multicolumn{7}{|l|}{ Escapism } \\
\hline 1. I use my smartphone to make myself feel better. & 34 & 25 & 64 & .73 & .19 & .12 \\
\hline $\begin{array}{l}\text { 2. I am less lonely when I am using my smartphone. } \\
\text { 7. When I am using my smartphone, I feel like I am }\end{array}$ & 36 & 31 & .60 & .70 & .20 & .15 \\
\hline somewhere else. & 27 & 16 & .53 & .70 & .11 & .07 \\
\hline 11. I use my smartphone to forget about real life. & 31 & 17 & .61 & .69 & 19 & 12 \\
\hline \multicolumn{7}{|l|}{ Online acceptance } \\
\hline $\begin{array}{l}\text { 5. I feel closer to people who I know from using my } \\
\text { smartphone than people in the real world. }\end{array}$ & 8 & 11 & .53 & .59 & .17 & .11 \\
\hline $\begin{array}{l}\text { 8. People I meet online using my smartphone are easier to } \\
\text { understand than real people. }\end{array}$ & 7 & 8 & .50 & .55 & .21 & .11 \\
\hline $\begin{array}{l}\text { 13. People I meet online accept me better than those in real } \\
\text { life. }\end{array}$ & 9 & 7 & .46 & .53 & .25 & .15 \\
\hline \multicolumn{7}{|l|}{ Offline disruption } \\
\hline $\begin{array}{l}\text { 18. My friends or family complain that I use my smartphone } \\
\text { too much. }\end{array}$ & 19 & 16 & .65 & .75 & .33 & .25 \\
\hline $\begin{array}{l}\text { 19. I have got into trouble with my friends or family because } \\
\text { of using my smartphone too much. }\end{array}$ & 22 & 16 & .58 & .69 & .25 & .18 \\
\hline
\end{tabular}

Note. $N=1,073$ for self-ratings; $\mathrm{N}=2,445$ for other ratings. Item text is shown for the selfreport format. Item Endorsement $\%$ is the percentage of responses that were agree or strongly agree for the item for self and other raters, respectively. Item-total $r$ is the correlations between the item and self and other total scores, respectively. Self-other $r$ is the self-other correlation for the item using the full 5-point response scale. Self-other kappa is Cohen's Kappa measure of agreement between self and other ratings after collapsing items to be a binary (strongly agree/agree versus the other response options). 


\section{Table 2}

Self-Other Correlations and Other-Rated Means and Standard Deviations for Subsets of OtherRaters for Problematic Smartphone Usage

\begin{tabular}{lcccc}
\hline Sample & $n$ & $M$ & $S D$ & $\begin{array}{c}\text { PSU } \\
\text { Self-other } \\
r\end{array}$ \\
\hline $\begin{array}{l}\text { All others } \\
\text { Cohabitation }\end{array}$ & 2545 & 2.28 & 0.87 & .38 \\
Cohabit & 840 & 2.38 & 0.92 & .44 \\
No cohabit & 1705 & 2.23 & 0.85 & .35 \\
Relationship & & & & \\
Parent & 624 & 2.26 & 0.91 & .41 \\
Partner & 468 & 2.36 & 0.89 & .41 \\
Sibling & 317 & 2.21 & 0.85 & .35 \\
Friend & 939 & 2.31 & 0.83 & .36 \\
Other & 197 & 2.12 & 0.92 & .39 \\
\hline
\end{tabular}

Note. Self-other $r$ is the correlation between self and other rating of problematic smartphone use (PSU) for the specified other rater type. 


\section{Table 3}

Correlations of Demographics and Personality Domains with Self and Other-Rated Problematic Smartphone Usage

\begin{tabular}{|c|c|c|c|c|c|c|}
\hline \multirow{2}{*}{ Predictor } & \multirow[b]{2}{*}{$\alpha$} & \multirow[b]{2}{*}{$\mathrm{M}$} & \multirow[b]{2}{*}{ SD } & \multicolumn{3}{|c|}{$r$ problematic smartphone use } \\
\hline & & & & $\begin{array}{l}\text { Self- } \\
\text { Rated } \\
\text { PSU }\end{array}$ & $\begin{array}{l}\text { Other- } \\
\text { Rated } \\
\text { PSU }\end{array}$ & $\begin{array}{c}\text { Combined } \\
\text { Other-Rated } \\
\text { PSU }\end{array}$ \\
\hline \multicolumn{7}{|l|}{ Demographics } \\
\hline Female & & 0.83 & 0.37 & .17 & .11 & .09 \\
\hline Age & & 25.60 & 8.67 & -.29 & -.20 & -.24 \\
\hline \multicolumn{7}{|l|}{ Big Five } \\
\hline Neuroticism & .87 & 2.91 & 0.73 & .41 & .22 & .26 \\
\hline Extraversion & .87 & 3.26 & 0.68 & -.16 & .03 & -.02 \\
\hline Openness & .73 & 3.79 & 0.50 & -.14 & -.09 & -.09 \\
\hline Agreeableness & .74 & 3.76 & 0.48 & -.19 & -.05 & -.13 \\
\hline Conscientiousness & .83 & 3.49 & 0.61 & -.36 & -.18 & -.22 \\
\hline \multicolumn{7}{|l|}{ HEXACO } \\
\hline Honesty-humility & .82 & 3.58 & 0.57 & -.32 & -.14 & -.18 \\
\hline Emotionality & .82 & 3.51 & 0.58 & .31 & .22 & .19 \\
\hline Extraversion & .86 & 3.17 & 0.61 & -.25 & -.07 & -.10 \\
\hline Agreeableness & .86 & 3.03 & 0.60 & -.23 & -.09 & -.15 \\
\hline Conscientiousness & .83 & 3.55 & 0.55 & -.28 & -.17 & -.19 \\
\hline Openness & .82 & 3.42 & 0.58 & -.16 & -.11 & -.09 \\
\hline
\end{tabular}

Note. $N=1,073$ for self-rated and combined-other rated PSU (i.e., where other ratings for focals with multiple other raters are averaged); $\mathrm{N}=2,445$ for other-rated PSU. Age and gender refer to demographics of focal participant. Female was coded Male $=0$, Female $=1$. PSU $=$ Problematic smartphone use. Correlations are the correlations between the predictor and the designated problematic smartphone use rating. 


\section{Table 4}

Correlations between Big Five Personality and Aspects of Problematic Smartphone Use

\begin{tabular}{lccccc}
\hline & Absorption & Addiction & Escapism & $\begin{array}{c}\text { Online } \\
\text { acceptance }\end{array}$ & $\begin{array}{c}\text { Offline } \\
\text { disruption }\end{array}$ \\
\hline $\begin{array}{l}\text { Self-rated problematic } \\
\text { smartphone use }\end{array}$ & & & & & \\
$\quad$ Neuroticism & .31 & .31 & .40 & .33 & .24 \\
Extraversion & -.08 & -.08 & -.21 & -.27 & -.01 \\
Openness & -.09 & -.17 & -.06 & -.07 & -.16 \\
Agreeableness & -.12 & -.19 & -.15 & -.19 & -.12 \\
Conscientiousness & -.35 & -.28 & -.28 & -.17 & -.23 \\
Other-rated problematic & & & & & \\
smartphone use & & & & .17 & .15 \\
Neuroticism & .20 & .17 & .20 & .17 & .05 \\
Extraversion & .04 & .07 & .01 & -.07 & -.10 \\
Openness & -.08 & -.12 & -.03 & -.06 & -.05 \\
Agreeableness & -.04 & -.05 & -.05 & -.03 & -.14 \\
Conscientiousness & -.21 & -.11 & -.14 & -.10 & \\
\hline
\end{tabular}

Note. $N=1,073$ for self-rated PSU; $N=2,445$ for other-rated PSU 


\section{Table 5}

Regression Models Predicting Problematic Smartphone Use (PSU) from Big Five Personality

\begin{tabular}{llll}
\hline & Self-Rated PSU & Other-Rated PSU & $\begin{array}{c}\text { Combined } \\
\text { Other-Rated PSU }\end{array}$ \\
\hline Neuroticism & $.33 * * *$ & $.25 * * *$ & $.24 * * *$ \\
Extraversion & .05 & $.17 * * *$ & $.13 * * *$ \\
Openness & $-.12 * * *$ & $-.08^{*}$ & $-.10 * *$ \\
Agreeableness & -.01 & .06 & -.01 \\
Conscientiousness & $-.26 * * *$ & $-.13 * * *$ & $-.17 * * *$ \\
Adjusted $R^{2}$ & $.24 * * *$ & $.08 * * *$ & $.10 * * *$ \\
\hline
\end{tabular}

Note. $N=1,073$ for self-rated and combined-other rated PSU (i.e., where other ratings for focals with multiple other raters are averaged); $\mathrm{N}=2,445$ for other-rated PSU. PSU = Problematic smartphone use.

$* p<.05, * * p<.01, * * * p<.001$. 


\section{Online Supplement}

Table S1.1 presents the domain-level and facet-level correlates for the HEXACO personality model. There were several differential patterns of facetcorrelations within domains. In particular, facets more closely related to neuroticism (or reversed neuroticism) tended to show larger correlations with problematic smartphone use. These include anxiety, social self-esteem and liveliness.

\section{Table S1.1}

HEXACO Domain and Facet Correlations with Self and Other-Rated Problematic Smartphone Usage

\begin{tabular}{|c|c|c|c|c|c|c|}
\hline & \multirow[b]{2}{*}{$\alpha$} & \multirow[b]{2}{*}{$M$} & \multirow[b]{2}{*}{$S D$} & \multicolumn{3}{|c|}{$\mathrm{r}$ with PSU } \\
\hline & & & & $\begin{array}{l}\text { Self- } \\
\text { Rated }\end{array}$ & $\begin{array}{l}\text { Other- } \\
\text { Rated }\end{array}$ & $\begin{array}{l}\text { Combined } \\
\text { Other } \\
\text { Ratings }\end{array}$ \\
\hline Honesty-humility & .82 & 3.58 & 0.57 & -.32 & -.15 & -.18 \\
\hline Emotionality & .82 & 3.51 & 0.58 & .31 & .18 & .19 \\
\hline Extraversion & .86 & 3.17 & 0.61 & -.25 & -.07 & -.10 \\
\hline Agreeableness & .86 & 3.03 & 0.60 & -.23 & -.11 & -.15 \\
\hline Conscientiousness & .83 & 3.55 & 0.55 & -.28 & -.15 & -.19 \\
\hline Openness & .82 & 3.42 & 0.58 & -.16 & -.09 & -.09 \\
\hline H1: Sincerity & .68 & 3.54 & 0.78 & -.25 & -.11 & -.11 \\
\hline H2: Fairness & .75 & 3.72 & 0.87 & -.27 & -.06 & -.15 \\
\hline H3: Greed-Avoidance & .80 & 3.17 & 0.90 & -.24 & -.17 & -.19 \\
\hline H4: Modesty & .68 & 3.90 & 0.69 & -.12 & -.05 & -.04 \\
\hline E1: Fearfulness & .70 & 3.15 & 0.82 & .24 & .16 & .12 \\
\hline E2: Anxiety & .75 & 3.85 & 0.81 & .32 & .21 & .21 \\
\hline E3: Dependence & .74 & 3.21 & 0.86 & .21 & .14 & .15 \\
\hline E4: Sentimentality & .66 & 3.82 & 0.72 & .12 & .13 & .08 \\
\hline X1: Social Self-Esteem & .71 & 3.47 & 0.73 & -.32 & -.11 & -.12 \\
\hline X2: Social Boldness & .75 & 2.84 & 0.85 & -.20 & -.08 & -.09 \\
\hline X3: Sociability & .74 & 3.15 & 0.82 & .03 & .07 & .05 \\
\hline X4: Liveliness & .76 & 3.23 & 0.79 & -.30 & -.09 & -.15 \\
\hline A1: Forgiveness & .78 & 2.61 & 0.82 & -.15 & -.04 & -.09 \\
\hline A2: Gentleness & .66 & 3.35 & 0.70 & -.11 & -.02 & -.06 \\
\hline A3: Flexibility & .65 & 3.00 & 0.73 & -.22 & -.07 & -.14 \\
\hline A4: Patience & .80 & 3.18 & 0.85 & -.21 & -.13 & -.15 \\
\hline $\mathrm{C} 1$ : Organization & .73 & 3.53 & 0.88 & -.20 & -.10 & -.13 \\
\hline C2: Diligence & .74 & 3.74 & 0.73 & -.26 & -.14 & -.17 \\
\hline C3: Perfectionism & .70 & 3.59 & 0.73 & -.07 & -.09 & -.08 \\
\hline C4: Prudence & .64 & 3.34 & 0.69 & -.28 & -.18 & -.18 \\
\hline O1: Aesthetic Appreciation & .67 & 3.46 & 0.85 & -.11 & -.11 & -.09 \\
\hline O2: Inquisitiveness & .71 & 3.23 & 0.87 & -.13 & -.06 & -.08 \\
\hline O3: Creativity & .75 & 3.39 & 0.86 & -.11 & -.07 & -.06 \\
\hline O4: Unconventionality & .55 & 3.58 & 0.59 & -.12 & -.06 & -.04 \\
\hline I: Altruism & .53 & 4.01 & 0.58 & -.13 & -.07 & -.13 \\
\hline
\end{tabular}


Table S1.2

Regression Models Predicting Problematic Smartphone Use from HEXACO Personality

\begin{tabular}{|l|l|l|l|}
\hline Predictor & $\begin{array}{c}\text { Self-Rated } \\
\text { PSU }\end{array}$ & $\begin{array}{c}\text { Other-Rated } \\
\text { PSU }\end{array}$ & \multicolumn{1}{|c|}{$\begin{array}{c}\text { Combined } \\
\text { Other-Rated PSU }\end{array}$} \\
\hline Honesty-humility & $-.25 * * *$ & $-.11^{* * *}$ & $-.12^{* * *}$ \\
\hline Emotionality & $.26 * * *$ & $.20 * * *$ & $.17 * * *$ \\
\hline Extraversion & $-.19 * * *$ & -.02 & -.04 \\
\hline Agreeableness & -.03 & .02 & -.05 \\
\hline Conscientiousness & $-.20 * * *$ & $-.12 * * *$ & $-.15 * * *$ \\
\hline Openness & $-.06 *$ & -.04 & -.04 \\
\hline & & & \\
\hline Adjusted $R^{2}$ & $.28^{* * *}$ & $.09 * * *$ & $.09 * * *$ \\
\hline
\end{tabular}

Note. $N=1,073$ for self-rated and combined other-rated PSU (i.e., where other ratings for focals with multiple other raters are averaged); $\mathrm{N}=2,445$ for other-rated PSU.

$* p<.05, * * p<.01, * * * p<.001$. 


\section{Factor Analysis}

Tables S2.1 to S2.4 show the results of maximum likelihood exploratory factor analysis of the problematic smartphone use items using promax rotation with loadings below .30 suppressed. Additional factor extractions are available through code provided in the OSF repository.

\section{Table S2.1}

Two factor Solution for Self-Ratings

Loadings:

9. When I can't use my smartphone I get restless or irritable.

Factor1 Factor2

12. I feel a buzz of excitement when on my smartphone.

$0.507 \quad 0.186$

14. I spend too much time on my smartphone.

$0.518 \quad 0.118$

15. I find myself thinking or saying "just a f

$0.908-0.233$

16. I stay on my smartphone longer than I mean to.

17. I go to bed late because I have been using my smartphone.

$0.772-0.121$

18. My friends or family complain that I use my smartphone too much.

$0.884-0.268$

$0.731-0.130$

$0.563 \quad 0.084$

19. I have got into trouble with my friends or family because of using my smartphone too much. $0.502 \quad 0.066$

20. I lose track of time when I am using my smartphone.

$0.837-0.212$

21. I use my smartphone even if I have more important things to do

$0.799-0.188$

5. I feel closer to people who I know from using my smartphone than people in the real world.

8. People I meet online using my smartphone are easier to understand than real people.

13. People I meet online accept me better than those in real life.

$-0.143 \quad 0.811$

1. I use my smartphone to make myself feel better.

2. I am less lonely when I am using my smartphone.

3. When I try to reduce my smartphone use I feel anxious (worried).

4. When I am not using my smartphone, I keep thinking about it.

$-0.316 \quad 0.993$

6. I feel bad when I cannot use my smartphone.

7. When I am using my smartphone, I feel like I am somewhere else.

10. I feel most pleasure when using my smartphone.

11. I use my smartphone to forget about real life.

$\begin{array}{lrr} & \text { Factor1 } & \text { Factor2 } \\ \text { SS loadings } & 6.546 & 3.473 \\ \text { Proportion Var } & 0.312 & 0.165 \\ \text { Cumulative Var } & 0.312 & 0.477\end{array}$

Factor Correlations: Factor1 Factor2

Factor1 $1.000 \quad 0.677$

Factor2 $\quad 0.677 \quad 1.000$ 


\section{Table S2.2}

Two factor Solution for Other-Ratings Loadings:

14. I spend too much time on my smartphone.

15. I find myself thinking or saying "just a few more minutes" when using my smartphone.

Factor1 Factor2

$0.888-0.086$

0.6260 .131

$0.893-0.122$

$0.709-0.018$

17. I go to bed late because I have been using my smartphone.

$0.786-0.038$

18. My friends or family complain that I use my smartphone too much.

$0.727-0.063$

19. I have got into trouble with my friends or family because of using my smartphone too much.

20. I lose track of time when I am using my smartphone.

$0.745-0.032$

21. I use my smartphone even if I have more important things to do

$0.776-0.059$

$0.185 \quad 0.574$

I use my smartphone to make myself feel better

$-0.190 \quad 0.829$

$-0.265 \quad 0.899$

8. People I meet online using my smartphone are easier to understand than real people.

0.045

$-0.200$

0.263

0.297

0.398

0.402

0. 312

0.479

0.264

0.366

9. When I can't use my smartphone I get restless or irritable.

0.312

11. I use my smartphone to forget about real life.

12. I feel a buzz of excitement when on my smartphone.

0.477

Factor1 Factor2

$\begin{array}{lll}\text { SS loadings } & 5.974 & 4.283 \\ \text { Proportion Var } & 0.284 & 0.204 \\ \text { Cumulative Var } & 0.284 & 0.488\end{array}$

Factor Correlations: Factor1 Factor2

Factor1 $\quad 1.00 \quad-0.74$

Factor2 $\quad-0.74 \quad 1.00$ 


\section{Table S2.3}

Five Factor Solution for Self-Ratings

Loadings:

14. I spend too much time on my smartphone.

15. I find myself thinking or saying "just a few more minutes" when using my smartphone.

Factor1 Factor2 Factor3 Factor4 Factor5

16. I stay on my smartphone longer than I mean to.

17. I go to bed late because I have been using my smartphone.

20. I lose track of time when I am using my smartphone.

21. I use my smartphone even if I have more important things to do

3. When I try to reduce my smartphone use I feel anxious (worried).

4. When I am not using my smartphone, I keep thinking about it.

6. I feel bad when I cannot use my smartphone.

9. When I can't use my smartphone I get restless or irritable.

1. I use my smartphone to make myself feel better.

7. When I am using my smartphone, I feel like I am somewhere else.

11. I use my smartphone to forget about real life.

5. I feel closer to people who I know from using my smartphone than people in the real world.

8. People I meet online using my smartphone are easier to understand than real people.

13. People I meet online accept me better than those in real life.

18. My friends or family complain that I use my smartphone too much.

$\begin{array}{lllll}0.809 & -0.025 & -0.007 & 0.000 & 0.043\end{array}$

$\begin{array}{lllll}0.555 & 0.144 & 0.082 & -0.025 & -0.022\end{array}$

$\begin{array}{lllll}0.909 & -0.074 & -0.077 & 0.025 & -0.026\end{array}$

$\begin{array}{lllll}0.615 & 0.039 & 0.014 & 0.029 & 0.011\end{array}$

$\begin{array}{lllll}0.710 & -0.086 & 0.140 & -0.036 & 0.005\end{array}$

$\begin{array}{lllll}0.681 & 0.106 & -0.037 & -0.001 & -0.038\end{array}$

$\begin{array}{lllll}-0.032 & 0.696 & 0.089 & -0.017 & -0.002\end{array}$

$\begin{array}{lllll}0.062 & 0.678 & 0.006 & -0.001 & -0.027\end{array}$

$\begin{array}{lllll}-0.086 & 0.854 & -0.052 & 0.014 & -0.003\end{array}$

$\begin{array}{lllll}0.030 & 0.929 & -0.136 & -0.019 & -0.067\end{array}$

$\begin{array}{lllll}-0.076 & -0.062 & 0.785 & -0.002 & 0.052\end{array}$

$\begin{array}{lllll}0.061 & -0.066 & 0.632 & -0.040 & -0.054\end{array}$

$\begin{array}{lllll}0.033 & -0.173 & 0.783 & 0.036 & -0.025\end{array}$

$\begin{array}{lllll}0.036 & 0.092 & 0.083 & 0.629 & -0.055\end{array}$

$\begin{array}{lllll}0.001 & -0.005 & -0.020 & 0.874 & 0.014\end{array}$

$\begin{array}{lllll}-0.008 & -0.055 & 0.009 & 0.834 & 0.011\end{array}$

$\begin{array}{lllll}0.002 & -0.061 & 0.026 & 0.000 & 1.021\end{array}$

19. I have got into trouble with my friends or family because of using my smartphone too much.

2. I am less lonely when I am using my smartphone.

10. I feel most pleasure when using my smartphone.

12. I feel a buzz of excitement when on my smartphone.

$\begin{array}{lllll}0.100 & 0.126 & -0.049 & 0.026 & 0.569\end{array}$

$\begin{array}{lllll}0.008 & 0.101 & 0.496 & 0.059 & -0.021\end{array}$

$\begin{array}{lllll}-0.098 & 0.303 & 0.332 & 0.074 & 0.082\end{array}$

$0.035-0.238-0.472-0.120-0.034$

$\begin{array}{lrrrrr} & \text { Factor1 } & \text { Factor2 } & \text { Factor3 } & \text { Factor4 } & \text { Factor5 } \\ \text { SS loadings } & 3.183 & 2.812 & 2.279 & 1.886 & 1.393 \\ \text { Proportion Var } & 0.152 & 0.134 & 0.109 & 0.090 & 0.066 \\ \text { Cumulative Var } & 0.152 & 0.285 & 0.394 & 0.484 & 0.550\end{array}$

Factor Correlations:

Factor1 Factor2 Factor3 Factor4 Factor5

$\begin{array}{llllll}\text { Factor1 } & 1.000 & 0.484 & 0.306 & -0.613 & -0.535\end{array}$

Factor2 $\quad 0.484 \quad 1.000 \quad 0.550 \quad-0.742 \quad-0.659$

$\begin{array}{llllll}\text { Factor3 } & 0.306 & 0.550 & 1.000 & -0.465 & -0.270\end{array}$

$\begin{array}{llllll}\text { Factor4 } & -0.613 & -0.742 & -0.465 & 1.000 & 0.633\end{array}$

Factor5 $\quad-0.535 \quad-0.659 \quad-0.270 \quad 0.633 \quad 1.000$ 


\section{Table S2.4}

Five factor Solution for Other-Ratings

Loadings:

14. I spend too much time on my smartphone.

15. I find myself thinking or saying "just a few more minutes" when using my smartphone.

Factor1 Factor2 Factor3 Factor4 Factor5

16. I stay on my smartphone longer than I mean to.

17. I go to bed late because I have been using my smartphone.

20. I lose track of time when I am using my smartphone.

21. I use my smartphone even if I have more important things to do

3. When I try to reduce my smartphone use I feel anxious (worried).

4. When I am not using my smartphone, I keep thinking about it.

6. I feel bad when I cannot use my smartphone.

9. When I can't use my smartphone I get restless or irritable.

5. I feel closer to people who I know from using my smartphone than people in the real world.

8. People I meet online using my smartphone are easier to understand than real people.

13. People I meet online accept me better than those in real life.

1. I use my smartphone to make myself feel better.

18. My friends or family complain that I use my smartphone too much.

$\begin{array}{lllll}0.615 & 0.251 & -0.051 & -0.116 & 0.140\end{array}$

$\begin{array}{lllll}0.508 & 0.344 & 0.040 & -0.061 & -0.067\end{array}$

$\begin{array}{lllll}0.990 & -0.106 & -0.043 & -0.010 & -0.026\end{array}$

$\begin{array}{lllll}0.695 & 0.101 & 0.006 & -0.047 & -0.053\end{array}$

$\begin{array}{lllll}0.866 & -0.105 & 0.041 & -0.010 & -0.050\end{array}$

$\begin{array}{lllll}0.785 & -0.127 & -0.028 & 0.076 & 0.056\end{array}$

$\begin{array}{lllll}0.018 & 0.738 & 0.212 & -0.120 & -0.082\end{array}$

$\begin{array}{llllll}0.067 & 0.673 & 0.088 & -0.022 & -0.039\end{array}$

$\begin{array}{lllll}-0.093 & 0.809 & -0.113 & 0.182 & -0.024\end{array}$

$\begin{array}{lllll}-0.092 & 0.689 & -0.062 & 0.132 & 0.158\end{array}$

$\begin{array}{lllll}-0.050 & -0.005 & 0.721 & 0.023 & 0.028\end{array}$

$\begin{array}{rrrrr}-0.050 & -0.005 & 0.721 & 0.023 & 0.028 \\ -0.012 & 0.013 & 0.985 & -0.192 & -0.075\end{array}$

$\begin{array}{lllll}-0.054 & -0.142 & 0.723 & 0.075 & 0.080\end{array}$

$\begin{array}{lllll}-0.073 & 0.132 & -0.095 & 0.885 & -0.036\end{array}$

$\begin{array}{lllll}0.047 & 0.002 & -0.022 & -0.020 & 0.945\end{array}$

19. I have got into trouble with my friends or family because of using my smartphone too much. $0.205 \quad 0.146 \quad-0.003 \quad-0.102 \quad 0.525$

2. I am less lonely when I am using my smartphone.

7. When I am using my smartphone, I feel like I am somewhere else.

$\begin{array}{lllll}0.153 & 0.133 & 0.087 & 0.421 & -0.024\end{array}$

10. I feel most pleasure when using my smartphone.

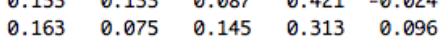

11. I use my smartphone to forget about real life.

$\begin{array}{lllll}0.001 & 0.173 & 0.447 & 0.112 & 0.036\end{array}$

12. I feel a buzz of excitement when on my smartphone.

$\begin{array}{lllll}0.204 & -0.012 & 0.117 & 0.499 & -0.015 \\ 0.144 & 0.334 & 0.069 & 0.193 & 0.013\end{array}$

$\begin{array}{lrrrrr} & \text { Factor1 } & \text { Factor2 } & \text { Factor3 } & \text { Factor4 } & \text { Factor5 } \\ \text { SS loadings } & 3.655 & 2.582 & 2.347 & 1.501 & 1.262 \\ \text { Proportion Var } & 0.174 & 0.123 & 0.112 & 0.071 & 0.060 \\ \text { Cumulative Var } & 0.174 & 0.297 & 0.409 & 0.480 & 0.540\end{array}$

Factor Correlations:

Factor1 Factor2 Factor3 Factor4 Factor5

$\begin{array}{llllll}\text { Factor1 } & 1.000 & 0.479 & -0.704 & -0.738 & -0.514\end{array}$

$\begin{array}{llllll}\text { Factor2 } & 0.479 & 1.000 & -0.603 & -0.698 & -0.757\end{array}$

$\begin{array}{llllll}\text { Factor3 } & -0.704 & -0.603 & 1.000 & 0.793 & 0.716\end{array}$

$\begin{array}{llllll}\text { Factor4 } & -0.738 & -0.698 & 0.793 & 1.000 & 0.766\end{array}$

$\begin{array}{llllll}\text { Factor5 } & -0.514 & -0.757 & 0.716 & 0.766 & 1.000\end{array}$

